\title{
On the Faceting of Alumina Surfaces
}

\author{
Shelley R. Gilliss, Jessica Riesterer, Arzu Altay and C. Barry Carter \\ Dept. of Chemical Engineering and Materials Science, University of Minnesota \\ 421 Washington Ave. S.E., Minneapolis MN 55455 USA
}

Surfaces of ceramics, semiconductors and metals can each undergo the phenomenon of faceting. In the case of the m-plane (1010) of alumina it has been shown to facet into a hill-and-valley morphology [1]. However, the mechanism by which a material transforms from a flat surface to the final low-energy state is not well understood. TEM investigations of the dewetting behavior of $\mathrm{CaAl}_{2} \mathrm{Si}_{2} \mathrm{O}_{8}$ glass on $\mathrm{m}$-plane alumina indicate that when diffusion is enhanced (in the presence of

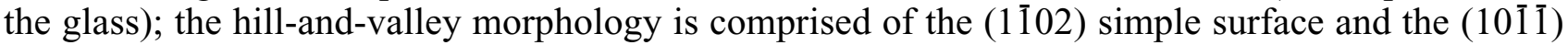
complex surface [2]. The complex surface, along with the simple surface, is present when reconstruction occurs beneath a glass droplet (and where diffusion is a maximum). Faceting, which occurs outside of the glass droplet, consists of different surfaces due to slower kinetics [3]. The present study investigates facet interactions and facet evolution by observing the same facets after additional heat treatments. The ability to revisit the same facet after further heat treatments is possible by placing fiducial marks on the surface. In this case a gravity-loaded indenter has been used to make such markers. This technique has enabled the evolution of the faceting on the m-plane of alumina to be observed.

Alumina $\left(\mathrm{Al}_{2} \mathrm{O}_{3}\right)$ samples were prepared from as-received, polished single crystals with a nominal (1010) surface orientation. A series of indents were made on the single-crystal substrates to enable the same region to be recognized after repeated heat-treatments. After indentation, the alumina specimens were first characterized by atomic-force microscopy (AFM) to determine the surface morphology prior to heat treatment and were found to be smooth ( $R \max =1.1 \mathrm{~nm}$ ), with only traces of polishing damage visible. The crucible and specimen were placed in the furnace at temperature $\left(1400^{\circ} \mathrm{C}\right)$ and removed from the furnace at temperature. An initial heat-treatment of 10 minutes was used, followed by additional heat treatments of a minute each. AFM characterization was carried out in contact mode on a Nanoscope III system (Digital Instruments) using $\mathrm{Si}_{3} \mathrm{~N}_{4}$ cantilevers. Figure 1 is an AFM height image of an area located within the marked quadrant. This sample was heat treated for 10 minutes at $1400^{\circ} \mathrm{C}$. Individual facets and facet domains are present. Facet domains are concentrated around the indented regions. The highlighted facet in Figure 1 was revisited after subsequent heat treatments. Figures 2(a) and 2(b) are sections of facet A looking down the [1 210$]$ direction. This facet contains a simple and complex surface. Previous studies have shown the simple surface is the (1102) plane, which is labeled in the figure [4]. In the present study, after an additional one minute at $1400^{\circ} \mathrm{C}(2(\mathrm{~b}))$ (a total time of 11 minutes) the surface of alumina enters a roughening stage. Small facets nucleated on the entire surface of the sample, while the pre-existing facet has grown in height and width. Observation of the same facets after repeated heat treatments show the simple surface remains while the complex surface transforms to a lower energy state. It is possible to observe an individual facet and facet domains after subsequent heat treatments by using fiducial marks on a specimen. When indents are used as fiducial markers, the damage induced by the indentation process may influence the faceting rate of the surface which will complicate the interpretation of the observed nucleation and growth of faceting. The m-plane of alumina facets into a simple and complex surface. The simple surface forms immediately and is stable throughout subsequent heat treatments. Although the complex surface transforms to a lower energy state over subsequent heat treatments and acts as a nucleation site for new facet growth, these results must be interpreted carefully. The time scale of the reconstruction and faceting is likely due to contamination or damage induced by the indentation process. 


\section{References}

1. J. R. Heffelfinger et al., Surf. Sci., 343 (1995) L1161.

2. M. P. Mallamaci and C.B. Carter, Acta Mater., 46 (1998) 2895.

3. S. R. Gilliss, et al., Microsc. Microanal., 8 (2002) (Suppl. 2) 562CD.

4. J. R. Heffelfinger and C.B. Carter, Surf. Sci., 389 (1997) 1.

5. This research has been supported by the U.S. Department of Energy through grant DE-FG02-01ER45883.

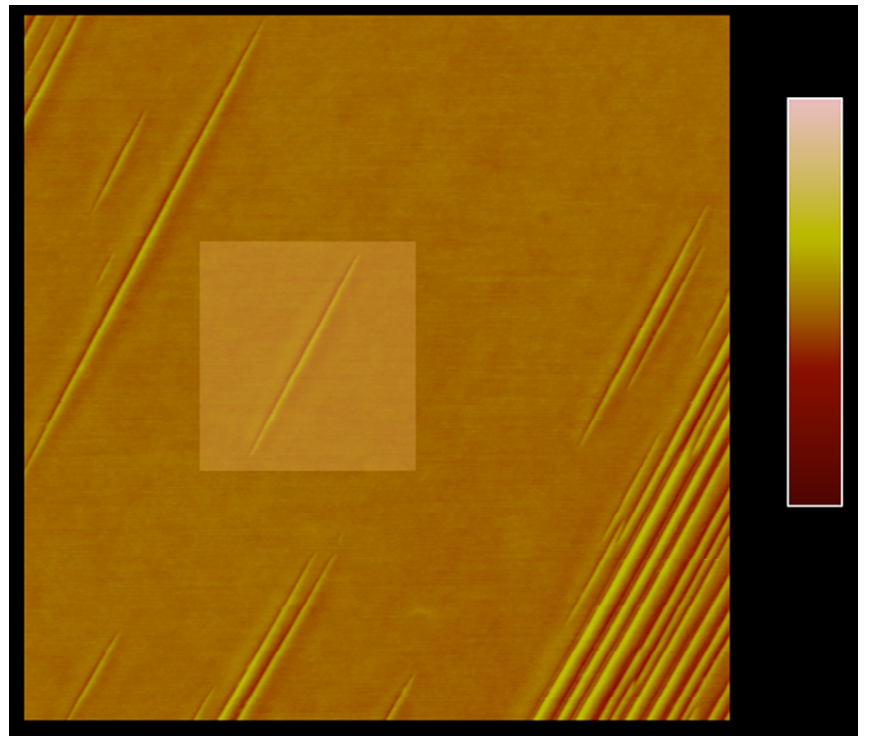

Fig.1. AFM image of the m-plane of alumina after a heat treatment of 10 minutes at $1400^{\circ} \mathrm{C}$. The highlighted facet is seen in line profile in Figure 2. The area of the micrograph is $5 \mu \mathrm{m} x$ $5 \mu \mathrm{m}$ and the height scale is $20 \mathrm{~nm}$.

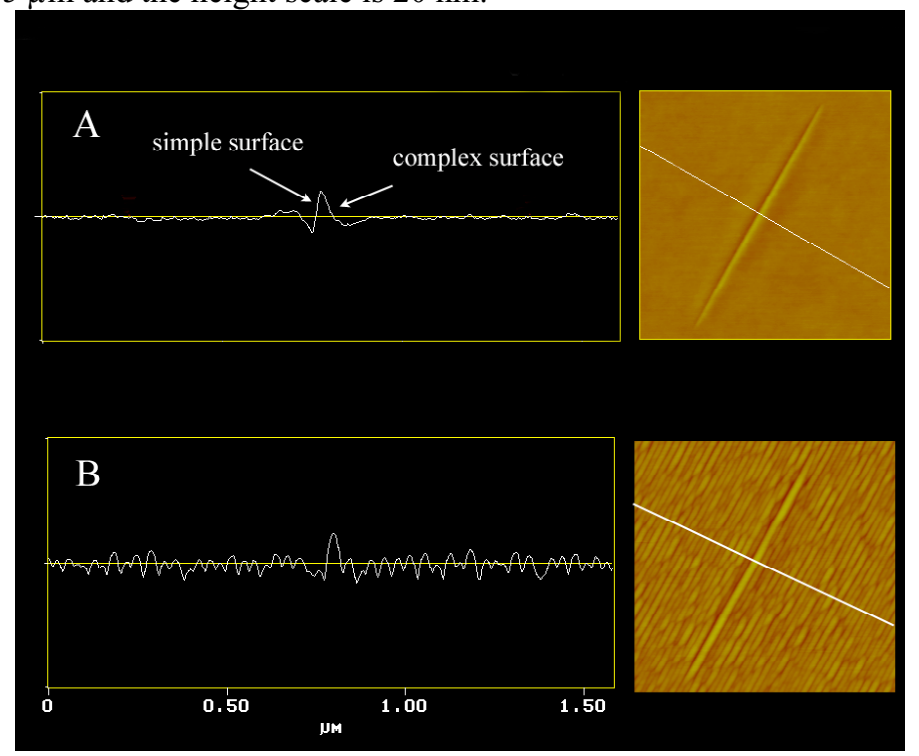

Fig. 2. Line profile of the same facet after (a) 10 minutes at $1400^{\circ} \mathrm{C}$ and (b) one additional minute at $1400^{\circ} \mathrm{C}$. 